\title{
Subunit Structure of Cholera Toxin
}

\author{
By I. LÖNNROTH AND J. HOLMGREN* \\ Institute of Medical Microbiology, University of Göteborg, \\ S-4I3 46 Göteborg, Sweden
}

(Received I January 1973; revised I 2 February 1973)

\begin{abstract}
SUMMAR Y
Two types of subunit, with molecular weights estimated to be 28000 and 8000 , were demonstrated in the cholera exo-enterotoxin by sodium dodecylsulphate polyacrylamide electrophoresis. The light $(\mathrm{L})$ component but not the heavy $(\mathrm{H})$ was demonstrable in the antigenically identical natural toxoid. A split of the $\mathbf{H}$ component by reduction and alkylation suggested it to be a disulphide-bridged dimer.

Gel filtration at acid $\mathrm{pH}$ permitted separation of the $\mathrm{H}$ and $\mathrm{L}$ subunits in isolated form. Fractions with isolated subunits were non-toxic (skin test), in contrast to fractions with intermediate filtration rate containing both subunits. Fractions with a $\mathrm{L}: \mathrm{H}$ ratio of about 3.5 were even more toxic than the intact toxin ( $\mathrm{L}: \mathrm{H}$ ratio about 2 ). Addition of the isolated subunits to toxic fractions generally caused inhibition and only exceptionally potentiation of toxicity.

The data suggest that the cholera toxin might consist of an aggregate of seven $\mathrm{L}$ and one $\mathrm{H}$ subunits while the natural toxoid seems composed of only the aggregated $\mathrm{L}$ chains.
\end{abstract}

\section{INTRODUCTION}

Bacterial strains of several species isolated from the stools of patients with diarrhoea produce exotoxin, which is likely to be the diarrhoeogenic agent (Pierce, Greenough \& Carpenter, 197I). Best studied is the cholera toxin, which has been isolated and found to be a neutral protein with a reported mol. wt of 84000 (Finkelstein \& LoSpalluto, I969; LoSpalluto \& Finkelstein, 1972). In some other bacterial exotoxins, e.g. diphtheria toxin, subunits have been characterized and their nature and aggregation state have been found critical for the behaviour of the toxins (van Heyningen, 1970). Therefore, increased knowledge of the structure, including possible subunits, of the cholera toxin could facilitate the understanding of the interaction between the toxin and the gut, which might shed light also on the pathogenesis of other enterotoxic enteropathies (Craig, 1972). The presence of subunits of uniform size in the cholera toxin as well as in its natural toxoid was recently reported (LoSpalluto \& Finkelstein, 1972). By sodium dodecylsulphate (SDS) polyacrylamide electrophoresis we found, however, two types of subunit with different sizes in the toxin whereas in the toxoid only one of these types was demonstrable (Holmgren, Lönnroth, Ouchterlony \& Svennerholm, 1972). In the present study the subunits are characterized chemically and immunologically, and their significance for toxic activity is studied.

\section{METHODS}

Cholera toxin. Isolated cholera toxin, choleragen, was prepared under contract for the National Institute of Allergy and Infectious Diseases by R. A. Finkelstein, The University of

\footnotetext{
* To whom reprint requests should be addressed.
} 
Texas Southwestern Medical School, Dallas, Texas, and had the lot no. I07I (Finkelstein \& LoSpalluto, 1970). In addition, another batch of toxin was used; this had been prepared by a method similar to that for lot 107I. The freeze-dried material was dissolved to give a solution $\left(0.5 \%\right.$, w/v) in sterile tris-EDTA buffer, $\mathrm{pH} 7.5$ (0.05 M-tris, 0.00I M-Na $\mathrm{N}_{2}$ EDTA, $0.003 \mathrm{M}-\mathrm{NaN}_{3}$ and $0.2 \mathrm{M}-\mathrm{NaCl}$ ) and dispensed in small volumes kept at $-30{ }^{\circ} \mathrm{C}$ until use.

All protein concentrations are expressed as $\%(w / v)$ unless otherwise noted.

Natural cholera toxoid. The isolated natural cholera toxoid (Finkelstein \& LoSpalluto, I969) was handled and stored in the same manner as the toxin but at $0.1 \%$ concentration.

Formalin toxoid. A formalin toxoid was prepared by treating a sample of the isolated toxin at $0.5 \%$ concentration with $0.2 \%$ formalin at $35{ }^{\circ} \mathrm{C}$ for 4 days.

Reference material and their molecular weights. Fresh human serum, human IgG (I 50000), human serum transferrin (88000), human serum albumin $(68000)$, ovalbumin $(46000)$, ribonuclease A from bovine pancrease (I4500) and cytochrome $c$ from equine heart (I 2400 ) were used as references in the SDS polyacrylamide eletrophoresis and gel filtration runs.

Antisera. Antisera to toxin and natural toxoid were prepared in rabbits by two subcutaneous injections of the materials (without adjuvant) with an interval of 3 weeks; io $\mu \mathrm{g}$ antigen were given in each injection. In addition were used rabbit antiserum to culture filtrate from Vibrio cholerae and equine antiserum to purified toxoid.

Reduction and alkylation. Reduction of protein disulphide bridges was performed with varying concentrations of freshly dissolved 2-mercapto-ethanol at $20^{\circ} \mathrm{C}$ for $90 \mathrm{~min}$ in $0.5 \mathrm{M}$-tris- $\mathrm{HCl}$ buffer at $\mathrm{pH} \mathrm{8.2.} \mathrm{The} \mathrm{reduced} \mathrm{proteins} \mathrm{were} \mathrm{then} \mathrm{alkylated} \mathrm{with} 0 . \mathrm{I} \mathrm{M}$ iodoacetamide in an ice-bath for $30 \mathrm{~min}$, desalted by filtration through a Sephadex G-25 column and then freeze-dried. In some instances the reduction was performed in the SDSurea solution described below.

SDS polyacrylamide electrophoresis. A modification of the method of Dunker \& Rueckert (1969) was employed. The gel $(7 \%, \mathrm{w} / \mathrm{v}$, polyacrylamide and $0.2 \%$ agarose in $0 . \mathrm{I}$ M-sodium

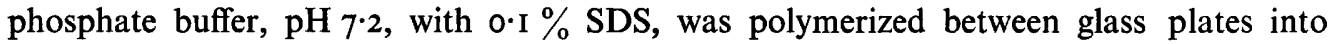
$2 \mathrm{~mm}$ thick layers. The same buffer was used as electrode solution. The gels were preelectrophoresed for $2 \mathrm{~h}$ for equilibration. The test proteins (native or reduced) were incubated in a solution of $8 \mathrm{M}$-urea, $2 \%$ SDS and $0.04 \mathrm{M}$-iodoacetamide, in most cases at $37^{\circ} \mathrm{C}$ for $30 \mathrm{~min}$; the protein concentration was generally in the range 0.04 to $0.20 \%$. After mixing with an equal volume of $3 \%$ agarose in the gel buffer, the test materials were applied as Io $\mu \mathrm{l}$ samples into rectangular basins cut in the gel plate; gel filtration fractions were applied without agarose.

The runs were performed overnight at room temperature with a current of $7 \mathrm{~mA} / \mathrm{cm}^{2}$. The plates were then stained with Coomassie Brilliant Blue. Included in at least two positions in each plate was a mixture of the reference proteins cytochrome $c$, ribonuclease $\mathrm{A}$, ovalbumin and transferrin, from which the mol. wt of the test substances were calculated by semilogarithmic plot (Dunker \& Rueckert, 1969). Quantitation of the Coomassie-stained spots was effected by a Vitatrone TLD I00 flying spot densitometer (Vitatrone N.V., Dieren, Holland) at $663 \mathrm{~nm}$.

Gel filtration. Gel filtration was done through a $15 \times 600 \mathrm{~mm}$ Sephadex G-I00 column with a flow rate of $10 \mathrm{ml} / \mathrm{h}$, using three different eluting buffers: $0 . \mathrm{I}$ M-tris- $\mathrm{HCl}, \mathrm{pH} \mathrm{7.5}$;

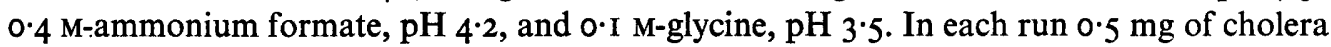
toxin, dissolved in the buffer, was applied and $2.6 \mathrm{ml}$ fractions were automatically collected. After dialysis (guaranteed pore size 24 A, Union Carbide, Chicago, Illinois, U.S.A.) against $0.05 \mathrm{M}$-ammonium acetate, $\mathrm{pH} \mathrm{6.5}$, the fractions were tested for protein content (Lowry, Rosebrough, Farr \& Randall, I966), antigen content (Laurell, 1966) and toxicity (Craig, 


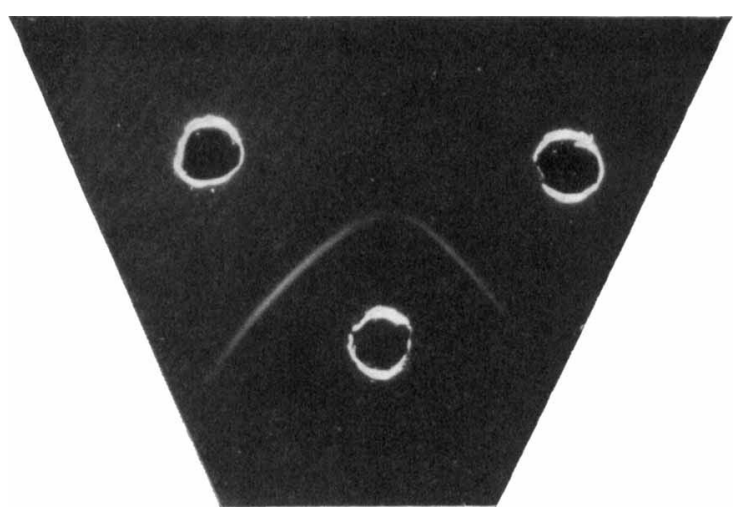

Fig. I. Comparative immunoprecipitation analysis of cholera toxin (upper right well) and natural toxoid (upper left well) with antiserum against toxin (lower well).

1965). A $0.5 \mathrm{ml}$ sample of each fraction was lyophilized and tested in SDS-polyacrylamide electrophoresis.

Thin-layer gel filtration in Sephadex G-200 (superfine) was performed according to Hanson, Holmgren \& Wadsworth (I97I). The test samples were applied in volumes of $7 \mu \mathrm{I}$ and run parallel with human serum and a mixture of reference proteins. Coomassie-stained paper replicas of the plates were used for registration of the gel filtration behaviour of the test proteins. Approximate mol. wt estimations were done from semilogarithmic plots.

Immunoprecipitation. A sensitive microplate modification of the Ouchterlony double diffusion technique (Wadsworth, 1957) was employed for qualitative analyses. Evaluation of antigen content of fractions was done with an electroimmunoassay (Laurell, 1966), where after staining with Coomassie Brilliant Blue the size of the rocket-shaped precipitates was graded,+++ or +++ , and the absence of a precipitate recorded - .

Toxicity assay. The rabbit-skin test of Craig (1965), in which toxicity is assessed as blueing doses (BD), was used. Neutralization inhibition was done by incubating toxin-neutralizing antiserum with antigenic material at $37^{\circ} \mathrm{C}$ for $30 \mathrm{~min}$, and assessing the effect on the neutralizing capacity of the antiserum in the skin toxicity assay (Craig, I965).

\section{RESULTS}

Immunological studies. The purity of cholera toxin and natural toxoid was tested by double diffusion analyses. With the antisera employed, prepared against the purified proteins as well as against culture filtrate from Vibrio cholerae, both proteins gave a single precipitation line, which in comparative double diffusion showed 'identity reactions' without spur formation (Fig. r). It was also possible to inhibit all of the reactive antibodies from antitoxin as well as antitoxoid antisera by incubation with the heterologous protein. This was assessed by immunoprecipitation as well as neutralization inhibition in toxicity assay.

SDS polyacrylamide electrophoresis. SDS polyacrylamide electrophoresis enabled studies of the proteins in a milieu where non-covalently bound subunits would be separated according to their molecular weights. With the cholera toxin (Fig. 2, position I) three main components were seen with the tentative mol. wt 8000,28000 and 82000 (Table I). In addition, fainter spots corresponding to mol. wt 18000 and 54000 were noted. Heat-treatment of the toxin did not affect the behaviour of the 28000 -dalton component but caused an increase of the 


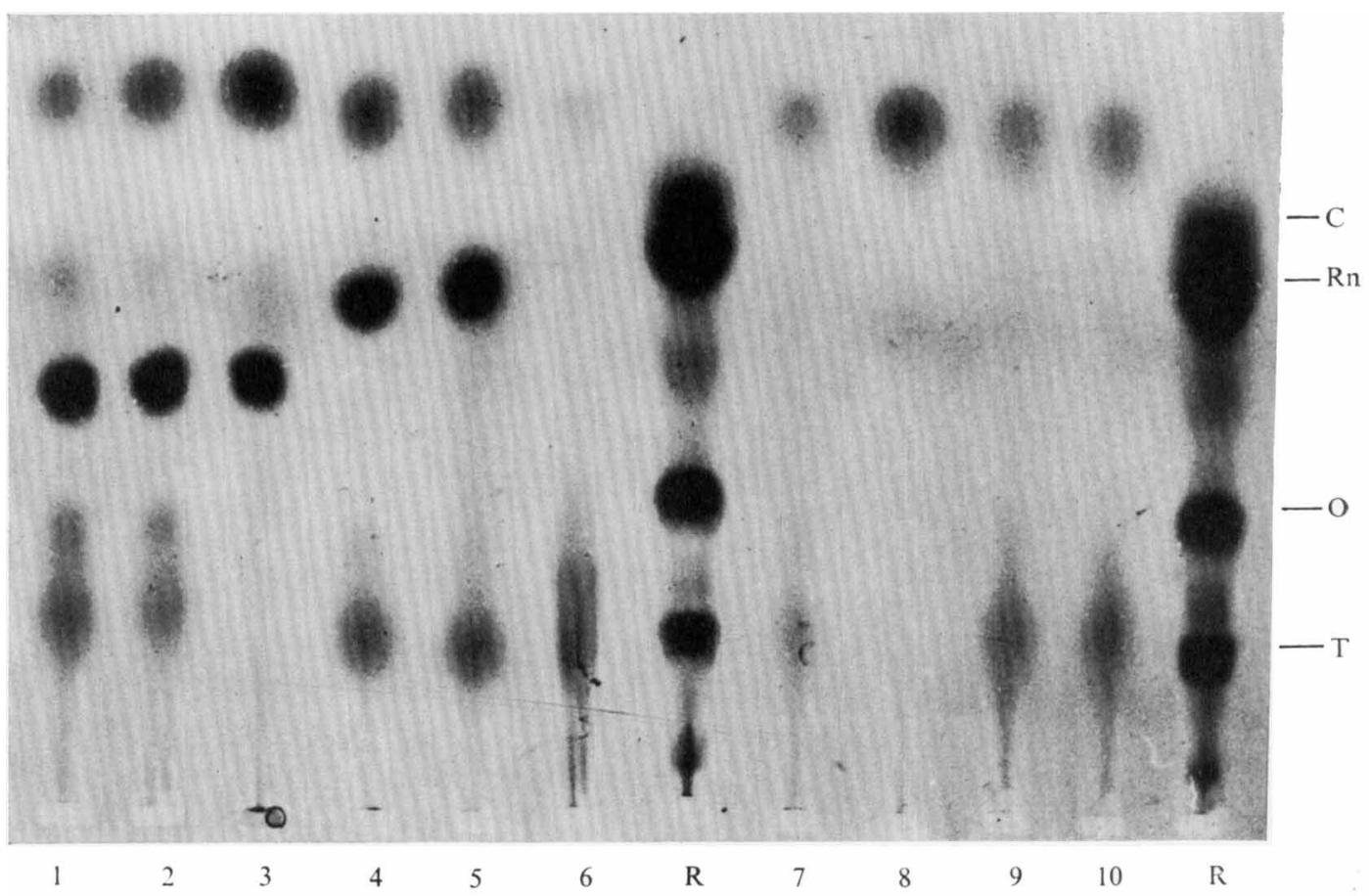

Fig. 2. SDS polyacrylamide electrophoresis analysis. Positions I to 5 : toxin incubated at $37^{\circ} \mathrm{C}$ (I), $42^{\circ} \mathrm{C}(2), 56^{\circ} \mathrm{C}$ (3) and 2-mercaptoethanol (ME)-treated (4 to 5). Positions 7 to I0: Natural toxoid at $37^{\circ} \mathrm{C}(7), 56^{\circ} \mathrm{C}(8)$ and after ME-treatment (9 to 10 ). Position 6 shows formalin toxoid. $R$, a mixture of the reference substances cytochrome $(C)$; ribonuclease $A(R n)$, ovalbumin $(O)$ and transferrin $(\mathrm{T})$.
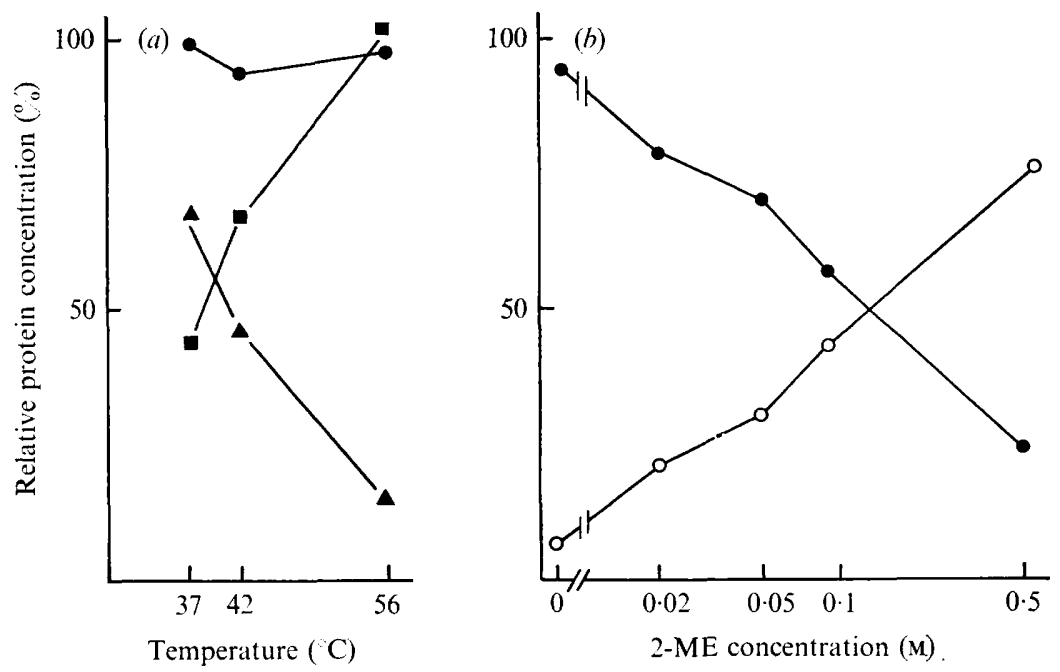

Fig. 3. Quantitative effects on toxin components by (a) temperature and (b) 2-mercaptoethanol (ME) treatment from densitometric evaluation of stained proteins in SDS polyacrylamide electrophoresis. $\Delta, 82000$-dalton component; $\square, 8000$-dalton component; $\bullet, 28000$-dalton component; O, 18000 -dalton component. 
Table I. Molecular weight estimations of subunits of cholera toxin and natural toxoid in SDS polyacrylamide electrophoresis

\begin{tabular}{|c|c|c|c|}
\hline \multirow[b]{2}{*}{ Material } & \multirow{2}{*}{$\begin{array}{c}\text { No. of } \\
\text { components }\end{array}$} & \multicolumn{2}{|c|}{ Mol. wt $\times 10^{3}$} \\
\hline & & Pre-ME & Post-ME \\
\hline Toxin & 5 & $\begin{array}{c}8 \\
18^{*} \\
28\end{array}$ & $\begin{array}{r}8 \\
18 \\
-\end{array}$ \\
\hline & & $\begin{array}{l}54 \\
82\end{array}$ & $\begin{array}{l}58 \\
92\end{array}$ \\
\hline Natural toxoid & 2 & $\begin{array}{r}8 \\
82\end{array}$ & $\begin{array}{r}8 \\
90\end{array}$ \\
\hline
\end{tabular}

Molecular weight values are means of several runs on unreduced (pre-ME) and 2-mercaptoethanol-treated (post-ME) samples.

8000-dalton component at the expense of the other bigger components (Fig. 2, positions 2 and 3). Reduction and alkylation of cholera toxin seemed to affect primarily the $28000-$ dalton component which was replaced by a component of mol. wt I 8000 (positions 4 and 5).

The natural cholera toxoid gave two spots in SDS polyacrylamide electrophoresis caused by components of mol. wt 8000 and 82000 (position 7). As with the toxin, mild heattreatment of the toxoid caused an increase of the 8000-dalton component and a disappearance of the ' 82000 spot' (position 8 ). Reduction and alkylation did not cause any marked changes in the behaviour of the toxoid in SDS electrophoresis (positions 9 to II).

With the formalin-induced toxoid, the bulk of material was of big but heterogeneous size, with mol. wt 52000 to 96000 (position 6).

The influence of heat and of reducing agent on the behaviour of the cholera toxin in SDS electrophoresis was analysed in more detail with densitometric quantitation of the protein spots. The heat-induced increase of the 8000-dalton component (Fig. 3a) quantitatively corresponded to the decrease of the ' 82000 spot', i.e. the latter spot was probably caused by aggregated 8000-dalton components which dissociate on mild heating. The ' 28000 spot' was unaffected by the heat treatment. On the other hand the 28000 -dalton component by reduction and alkylation was converted to 18000 -dalton components. This is seen in Fig. $3 b$, where a linear increase of the smaller component and a corresponding decrease of the 28000-dalton component occurred with a logarithmic increase of the concentration of reducing agent, i.e. the typical behaviour of oxidation-reduction reactions.

The described results were found with several vials of toxin from two different batches.

Gel filtration. Gel filtration of the toxin and the natural toxoid at $\mathrm{pH} 7.5$ in a thin layer of Sephadex G-200 (superfine) pointed to mol. wt values of 63000 and 48000 respectively. With the toxin in a column of Sephadex G-100 at $\mathrm{pH} 7.5$ both the toxicity and protein peaks corresponded to a mol. wt of about 50000 , but were notably broadened (Fig. $4 a$ ). At pH $4 \cdot 2$ the bulk of the protein filtered more slowly than the toxicity (Fig. $4 b$ ). This separation between toxicity and the bulk of protein material was also noted and accentuated at $\mathrm{pH} 3.5$ (Fig. $4 c$ ). The protein-containing fractions generally also contained antigen as judged from electroimmunoassays with anticulture filtrate antiserum (Fig. $4 a, b, c$ ).

$S D S$ electrophoresis of gel filtration fractions. Fractions from the column gel filtration of cholera toxin were analysed in SDS polyacrylamide electrophoresis to obtain information on their content of protein subunits. The pre-incubation of the fractions with the SDS-urea 

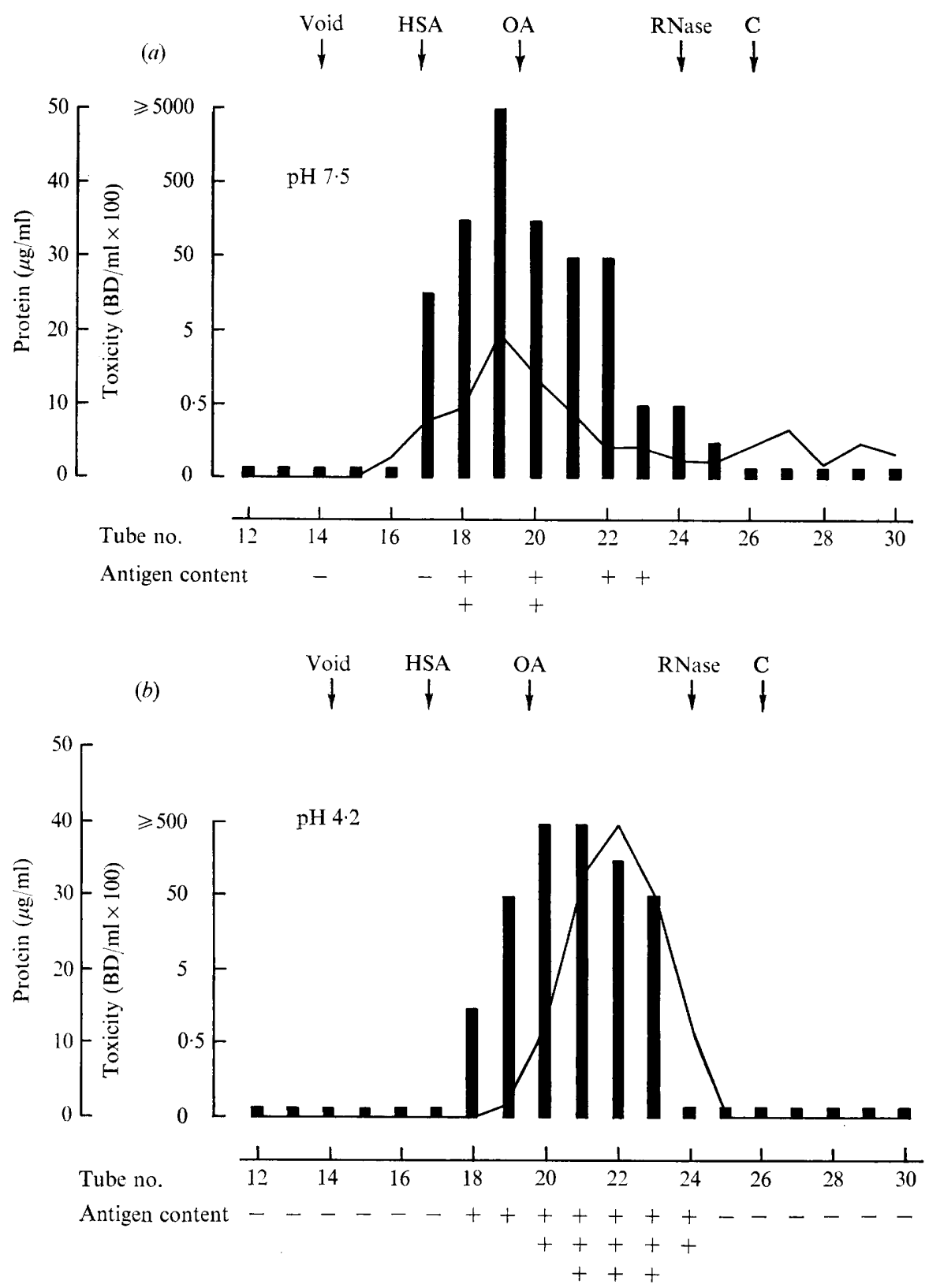

Fig. $4 a$ and $b$. For legend see facing page.

solution was performed at $56{ }^{\circ} \mathrm{C}$ to dissociate possibly aggregated 80oo-dalton subunits into the monomeric form. The content of 8000-dalton and 28000 -dalton subunits, from now on referred to as $\mathrm{L}$ and $\mathrm{H}$ components, in the fractions from various runs is shown in Fig. 5. At $\mathrm{pH} 7 \cdot 5$ the two subunits filtered together and their ratio was about 2: I (Fig. 5a), which was similar to the ratio of the subunits in the cholera toxin after similar heat treatment as determined in parallel runs. At $\mathrm{pH}_{4.2}$ the maximal level of the $\mathrm{H}$ subunit was in a faster filtering fraction than that containing the highest level of the $\mathrm{L}$ component, indicating a 


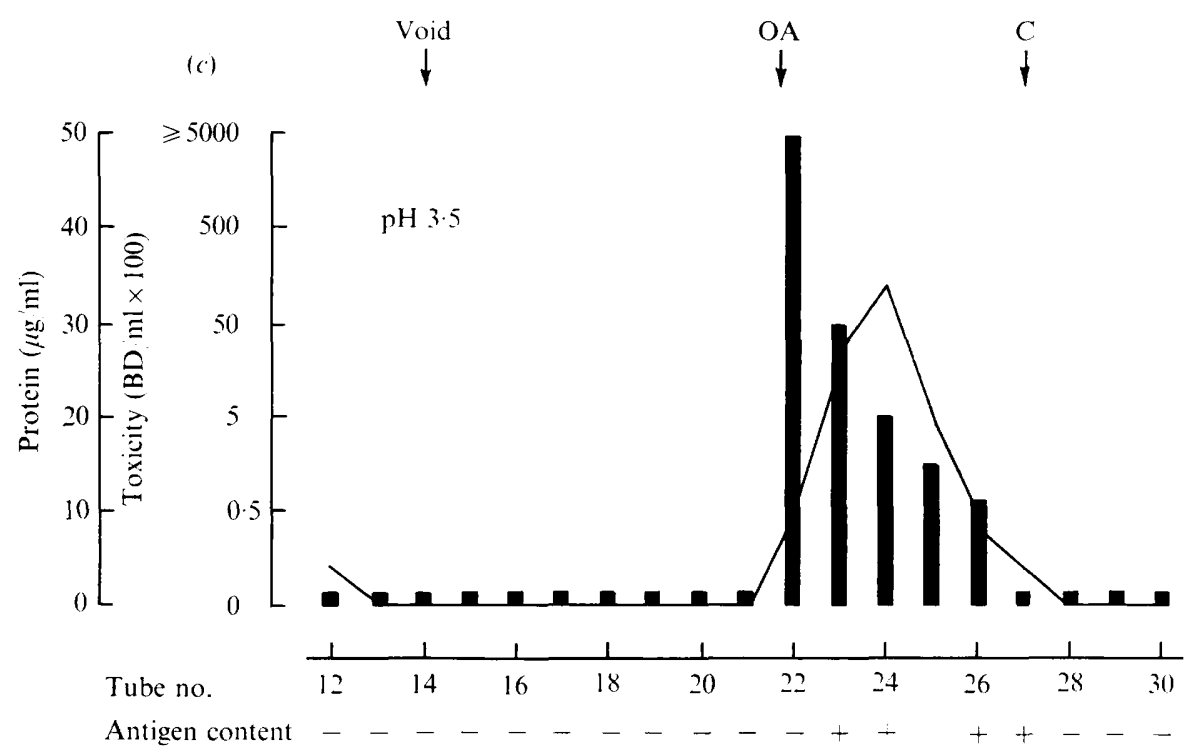

Fig. 4. Gel filtration of toxin through Sephadex G-100 at varying $\mathrm{pH}(a, b, c)$. Marker proteins were human IgG (void), human serum albumin (HSA), ovalbumin (OA), ribonuclease A (RNase) and cytochrome $c(C)$. Solid line represents protein content and the columns represent toxicity (blueing doses). The antigen content of fractions were assessed semiquantitatively by electroimmunoassay.

dissociation and separation of the two subunits (Fig. $5 b$ ). This dissociation and separation of $\mathrm{H}$ and $\mathrm{L}$ subunits was accentuated at $\mathrm{pH} 3.5$ (Fig. $5 c$ ), where it was possible to isolate $\mathrm{H}$ alone (tube no. 2I) and $\mathrm{L}$ alone (tube no. 26) (see photograph in Fig. 5c). After dialysis against neutral buffer, when tested in comparative double diffusion with rabbit antiserum to cholera toxin, the $L$ subunit gave a reaction of identity with the intact toxin while the $\mathbf{H}$ component, which was in low concentration, did not precipitate.

An experiment repeated in full with gel filtration at $\mathrm{pH} 3.5$ gave the same pattern with respect to protein content, antigen content, toxicity and composition of subunits in the fractions.

Toxicity in relation to subunit composition. Skin toxicity was only present in gel filtration fractions containing the $\mathrm{L}$ subunit as well as the $\mathrm{H}$ component (comparison of Fig. 4 and 5). The ratio of these subunits was critical for the toxicity expressed as number of blueing doses (BD) per ng of protein (Fig. 6). A ratio of about 3.5 was associated with high toxicity, while fractions with lower ratios had reduced activity and fractions with higher ratios had very low activity. Unfiltered toxin with a ratio about 2 showed also lower toxicity than fractions with a ratio about 3.5 .

The influence on the toxic activity of recombining different gel filtration fractions at pH 3.5 before or after dialysis against neutral buffer, was extensively studied. Significant inhibition of active fractions (fractions 22 from filtrations at $\mathrm{pH} 3.5$; Fig. 4 c) was generally obtained by combination with fractions of lower or no activity which had other subunit ratios. Up to 500-fold inhibition was obtained, being stronger the more $L$ subunit that was added. Inhibition was also noted when the fractions were combined after separate dialysis; 

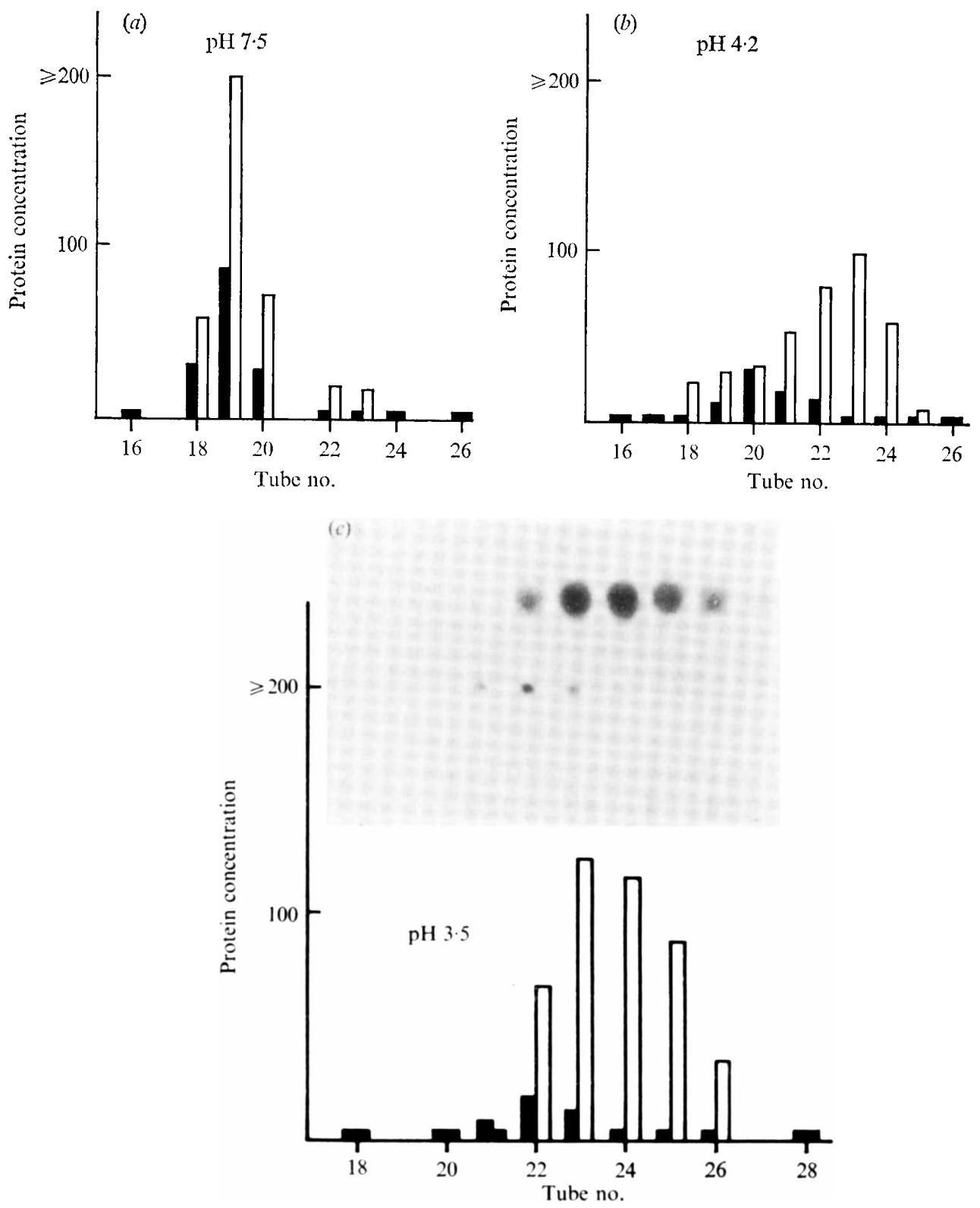

Fig. 5. Fractions from the gel filtration shown in Fig. 3 analysed by SDS polyacrylamide electrophoresis $(a, b, c)$ at varying $\mathrm{pH}$. Protein concentrations (densitometric units) of 28000 -daltoncomponent (solid columns) and 8000-dalton-component (open columns) in different fractions are shown and an illustrative photograph is inserted. 


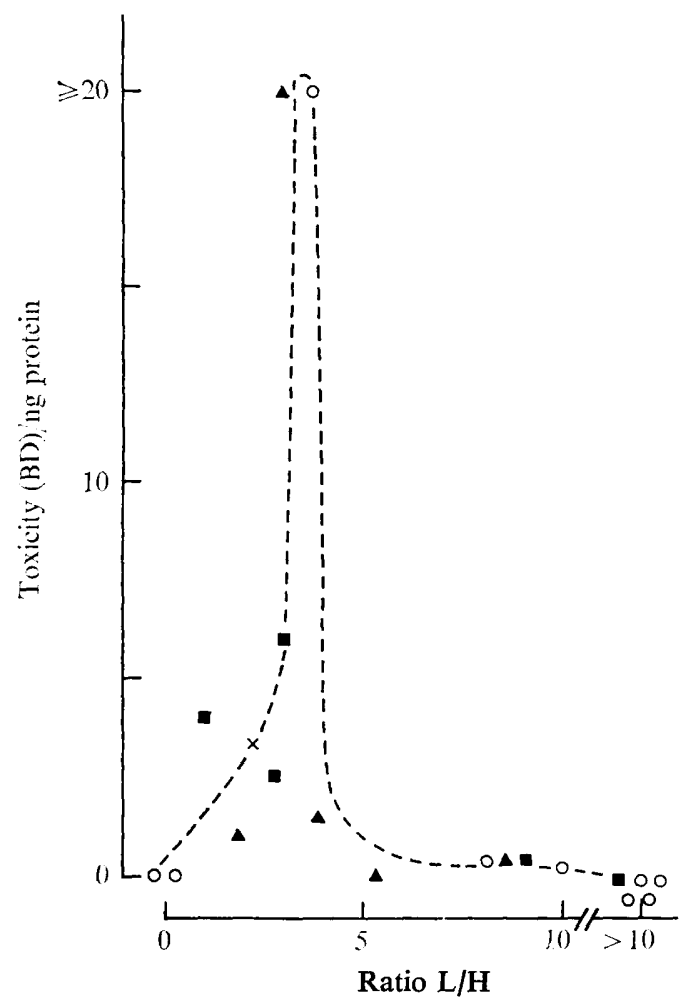

Fig. 6. Diagram of toxicity (blueing doses) in relation to the ratio of $\mathrm{L}$ and $\mathrm{H}$ subunits in different

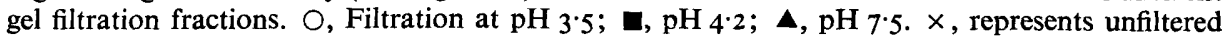
toxin. Dotted line is a possible interpretation of the data.

the inhibition capacity was, however, reduced during storage. Potentiation was observed on one occasion by adding isolated $\mathrm{H}$ subunit to a moderately toxic fraction but was not pronounced.

\section{DISCUSSION}

The concept that cholera exotoxin, choleragen, and its natural toxoid, choleragenoid, differ in size but not in antigenicity (Finkelstein \& LoSpalluto, I969; Holmgren, Lönnroth \& Ouchterlony, 197I) has been confirmed by us. However, the recent demonstration of amino acid differences between the two proteins (LoSpalluto \& Finkelstein, I972) indicated peptide differences between them. By use of SDS polyacrylamide electrophoresis, which permits dissociation and separation of non-covalently bound components, we were able to demonstrate two types of subunit in the toxin, only one of which was demonstrable in the toxoid. The toxin-specific subunit, $\mathrm{H}$, with an estimated mol. wt of 28000 , is probably a dimer with disulphide interchain bonds, since reduction with 2-mercaptoethanol caused its conversion to components with about half the mol. wt of the unreduced component. With the exception of the $\mathrm{H}$ component, the toxin as well as the toxoid appeared to be composed of identical subunits, $\mathrm{L}$, with an approximate mol. wt of 8000 . Spots indicative of material with mol. wt up to 82000 also seen in the SDS polyacrylamide electrophoresis tests probably represented aggregated forms of the $\mathrm{L}$ subunit since mild heating caused the larger components, noted in the toxin as well as toxoid, to dissociate into $\mathrm{L}$ chains. The $\mathrm{H}$ component was not affected by this heat-treatment. The toxoid induced by formalin treatment mainly 
consisted of aggregates which did not dissociate in SDS polyacrylamide electrophoresis. Probably this was due to formation of covalent inter- and intrachain bridges (Kabat \& Mayer, 196I).

Gel filtration through Sephadex G-Ioo showed that at neutral $\mathrm{pH}$ the two subunits of the cholera toxin filtered together, i.e. the ratio of the $\mathrm{L}$ to the $\mathrm{H}$ components on subsequent analysis in SDS electrophoresis was similar in all of the protein-containing fractions and similar to that of the unfiltered toxin. This does not exclude the possibility that, in the milieu employed, some dissociation and reaggregation occurred during the filtration which might explain the surprisingly broad peak observed. At $\mathrm{pH} 4.2$ and more pronounced at $\mathrm{pH} 3.5$, the protein was eluted in slower filtering fractions than at $\mathrm{pH} 7.5$, and at acid $\mathrm{pH}$ the two subunits varied in ratio in the different fractions, indicating disaggregation of the toxin and a more or less independent filtration of its two types of subunits. This permitted the separation and isolation of the faster filtering $\mathrm{H}$ component from the slower filtering $\mathrm{L}$ component. However, the recovery of the $\mathrm{H}$ component was comparatively poor, which might explain that only one size of subunit was demonstrated in ultracentrifuge analyses of cholera toxin in dissociating milieu (LoSpalluto \& Finkelstein, 1972). The purity of the cholera toxin and toxoid preparations has been assessed by various methods (Finkelstein \& LoSpalluto, 1970). It therefore does not seem likely that the toxin-specific $\mathrm{H}$ component was a contaminating substance but rather an integrated part of the toxin molecule, since it was demonstrated in several vials of two different batches. On this basis we favour the view that cholera toxin, like its natural toxoid, is composed of aggregated L subunits with mol. wt 8000 as judged from SDS electrophoresis but differs from the toxoid by the additional presence of the $\mathrm{H}$ subunit. Seven $\mathrm{L}$ chains associated with one $\mathrm{H}$ component would possibly give a molecule with the $84000 \mathrm{~mol}$. wt reported for the toxin from ultracentrifuge analyses (LoSpalluto \& Finkelstein, 1972) and this model would fit with the observed ratio 2: I of the $L$ and $H$ subunits in the toxin. Probably the $L$ chains and the $H$ component, the latter possibly a disulphide-bridged dimer, are held together with non-covalent bonds.

It is important to clarify the significance for toxicity of the two types of subunits in the toxin. The absence of the $\mathrm{H}$ component in the inactive toxoid suggests that this subunit directly or indirectly is responsible for the toxicity. However, the $\mathbf{H}$ subunit alone was inactive, as was also the isolated $\mathrm{L}$ subunit. Only fractions containing the $\mathrm{H}$ as well as the $\mathrm{L}$ subunits in a special ratio were highly active. This indicates that both subunits are essential for toxicity. The narrow range of ratios of the two subunits which was associated with high activity could mean that only at certain proportions is an aggregation state obtained that can attach to the postulated tissue receptor with enough affinity to induce the toxic action. This could fit with our observation that addition of the isolated subunits to toxic fractions at dissociating $\mathrm{pH}$ caused, in most instances, substantial inhibition of toxicity. However, also at neutral $\mathrm{pH}$, inhibition was noted by the addition of $\mathrm{L}$ subunits to toxic fractions. This makes it possible that the inhibition might have been caused by competitive inhibition at the toxin receptor level in the skin. Our recent finding of a ganglioside $\left(\mathrm{GM}_{1}\right.$, monosialosyl- $\mathrm{N}$ tetraglycosylceramide), which with high affinity binds to and inactivates the cholera toxin (Holmgren, Lönnroth \& Svennerholm, 1973) and which might represent the receptor, opens possibilities for more detailed studies of the interaction between the target cells and the toxin and its subunits.

We are grateful to Mrs Gun Wallerström for technical assistance and to Mr Charles Wadsworth for assistance with the thin-layer gel-filtration experiments. We thank Dr R. A. Finkelstein for a gift of isolated natural toxoid and toxin, and Dr R. Northrup for providing 
additional toxin from the National Institute of Allergy and Infectious Diseases. This study was supported by a grant (no. B 72-I6X-3382-03) from the Swedish Medical Research Council. One of us (J.H.) is the recipient of a research fellowship (no. B 72-40 P-359I-02) from this Council.

\section{REFERENCES}

CraIG, J. P. (1965). A permeability factor (toxin) found in cholera stools and culture filtrates and its neutralization by convalescent cholera sera. Nature, London 207, 614-6I6.

CraIG, J. P. (1972). The enterotoxic enteropathies. In Microbial Pathogenicity in Man and Animals, pp. 129I55. Edited by H. Smith and J. H. Pearce. Cambridge University Press.

DUNKER, A. K. \& RUECKeRT, R. R. (1969). Observations on molecular weight determinations on polyacrylamide gel. Journal of Biological Chemistry 244, 5074-5080.

Finkelstein, R. A. \& LoSpalluto, J. J. (1969). Pathogenesis of experimental cholera. Preparation and isolation of choleragen and choleragenoid. Journal of Experimental Medicine 130, 185-202.

Finkelstein, R. A. \& LoSpalluto, J. J. (1970). Production of highly purified choleragen and choleragenoid. Journal of Infectious Diseases 121, 63-72.

Hanson, L. Å., Holmgren, J. \& Wadsworth, C. (197I). A radial immuno-gel filtration method for characterization and quantitation of macromolecules. International Archives of Allergy and Applied Immunology 40, 806-819.

van Heyningen, W. E. (1970). General characteristics (of bacterial protein toxins). In Microbial Toxins, vol. I, pp. I-28. Edited by S. J. Ajl, S. Kadis and T. C. Montie. New York and London: Academic Press.

Holmgren, J., LöNNROth, I. \& OuChTERLONY, Ö. (197I). Immunochemical studies of two cholera toxincontaining preparations of Vibrio cholerae. Infection and Immunity 3, 747-755.

Holmgren, J., LöNNROTh, I., OUChTERLonY, Ö. \& SvenNERHOLM, A.-M. (1972). Studies on cholera toxins. Journal of General Microbiology 73, xxix.

Holmgren, J., LÖNNROTH, I. \& SVENNERHOLm, L. (1973). Fixation and inactivation of cholera toxin by $\mathrm{GM}_{1}$ ganglioside. Scandinavian Journal of Infectious Diseases $5,77-78$.

KABAT, E. A. \& MAYER, M. M. (1961). Experimental Immunochemistry, 2nd edn., pp. 458-46r. Springfield, Illinois: Charles C. Thomas.

LAURELL, C.-B. (1966). Quantitative estimation of proteins by electrophoresis in agarose gel containing antibodies. Analytical Biochemistry 15, 45-52.

LoSpalluto, J. J. \& Finkelstein, R. A. (1972). Chemical and physical properties of cholera exo-enterotoxin (choleragen) and its spontaneously formed toxoid (choleragenoid). Biochimica et biophysica acta $\mathbf{2 5 7}$, I58-I 66.

Lowry, O. H., Rosebrough, N. J., FarR, A. L. \& Randall, R. J. (1966). Protein measurement with the Folin phenol reagent. Journal of Biological Chemistry 193, 265-275.

Pierce, N. F., Greenough, W. B. III \& CARPenter, C. C. J. (I97I). Vibrio cholerae enterotoxin and its mode of action. Bacteriological Reviews 35, I-I3.

WADSWORTH, C. (I957). A slide microtechnique for the analysis of immune precipitates in gel. International Archives of Allergy and Applied Immunology Io, 355-360. 